\title{
Vasopressin and Prevention of Hypotension During Hemodialysis
}

\author{
Seyed Seifollah Beladi Mousavi ${ }^{1}$; Mohamad Reza Tamadon ${ }^{2, *}$ \\ ${ }^{1}$ Chronic Renal Failure Research Center, Jundishapur University of Medical Sciences, Ahvaz, IR Iran \\ ${ }^{2}$ Department of Internal Medicine, Faculty of Medicine, Semnan University of Medical Sciences, Semnan, IR Iran \\ ${ }^{*}$ Corresponding Author: Mohamad Reza Tamadon, Department of Internal Medicine, Faculty of Medicine, Semnan University of Medical Sciences, Semnan, IR Iran. Tel: +98- \\ 2333437822, Fax:+98-2333437838, E-mail:mrt_tamadon@yahoo.com
}

Received: May 31, 2014; Revised: July 12, 2014; Accepted: September 23, 2014

\begin{abstract}
Context: The occurrence of intradialytic hypotension (IDH) during hemodialysis (HD) continues to be a main problem in patients with ESRD (end-stage kidney disease). It also negatively affects health-related quality of life. We aimed to determine vasopressin effect in decreasing IDH.

Evidence Acquisition: We reviewed clinical and experimental literature in a variety of sources, including PubMed, Current Content, Scopus, Embase, and Iranmedex regarding the possible effect of vasopressin administration in prevention of hypotension during HD to clarify its mechanism, efficacy, and safety.

Results: Although arginine vasopressin is widely recognized for its anti-diuretic properties, it is also a well-recognized vasoconstrictor It has been shown that the vasopressin release (as it would normally be expected) does not increase in the majority of HD patients with recurrent dialysis hypotension. In addition, it has also been reported that vasopressin secretion (due to the osmotic stimulation) is the most important mechanism in blood pressure control in ESRD patients receiving hypertonic solution for IDH. Therefore, it is suggested that vasopressin administration may improve hemodynamic stability among ESRD patients during HD. There are few clinical trials about this issue, suggesting that administration of exogenous vasopressin may be significantly associated with a decreased incidence of IDH as well as cardiovascular stability in ESRD patients in need of volume removal during HD.

Conclusions: Vasopressin insufficiency may have an important role in the pathogenesis of hemodynamic instability during HD and administration of exogenous vasopressin is significantly associated with a lower incidence of IDH.
\end{abstract}

Keywords:Arginine Vasopressin; Hemodialysis; Hypotension

\section{Background}

Although significant technical improvements have made since the introduction of hemodialysis (HD) in the early 1950, many complications with different underlying mechanisms still occur during HD (1-15). Intradialytic hypotension(IDH), especially during ultrafiltration dialysis (in which fluid removal is the primary goal) continues to be a main problem, especially in the elderly, diabetic, and cardiovascular compromised patients $(16,17)$. Development of IDH usually necessitates blood flow reduction and sometimes, discontinuation of HD. Therefore, it is an important cause of inadequate dialysis among these patients.

On the other hand, in the patients who need ultrafiltration during HD, the development of hypotension necessitates intravenous fluid replacement and therefore, it causes volume overload and some other significant complications (17). Unfortunately, the incidence of this problem is very high and ranges from $15 \%$ to $50 \%$, especially among patients receiving ultrafiltration during HD (18). Many factors can contribute to hemodialysis hypotension, and they generally arise from these situations: fluid removal in an attempt to treat the volume overload and or to attain dry weight; reduction of plasma osmolality which causes water movement from extracellular space into the cells; use of a dialysate with low sodium concentration and or with acetate rather than bicarbonate as a dialysate buffer; reactions to the dialyzer membrane; use of antihypertensive medications and or ingestion of meal before or during HD session and cardiac arrhythmias or severe pericardial effusion with cardiac tamponade (12,16, 19-31).

According to above etiology, different strategies with variable success rate have been offered to prevent or diminish IDH such as increased dialysate sodium concentration and sodium modeling, combination of sodium modeling and ultra-filtration, use of bicarbonate instead of acetate as a dialysis buffer, avoidance of low magnesium and low calcium dialysate, use of low dialysate temperature, avoidance of antihypertensive medicines on dialysis day, and no food intake during dialysis (32-46). In addition, a number of pharmacologic agents such as midodrine, carnitine and intravenous mannitol, have also been evaluated in the prevention of IDH; however, because of a few comparative studies, there are no generally accepted guidelines for using these agents in prevention of hypotension during hemodialysis (47-51).

Copyright ( ) 2014, Iranian Red Crescent Medical Journal; Published by Kowsar. This is an open-access article distributed under the terms of the Creative Commons Attribution-NonCommercial 4.0 International License (http://creativecommons.org/licenses/by-nc/4.0/) which permits copy and redistribute the material just in noncommercial usages, provided the original work is properly cited. 
Vasopressin is a well-recognized vasoconstrictor, and the role of vasopressin insufficiency has also been proposed in hypotension during HD. Thus, it is possible that vasopressin administration may improve hemodynamic stability among patients with end-stage renal disease (ESRD) during HD (29, 52-54). This article reviewed and summarized some of the observations about the possible effect of vasopressin administration to prevent IDH episodes.

\section{Evidence Acquisition}

We used a variety of sources to collect current data for this review article. Published articles of PubMed, Embase, Scopus, Current Content, SID, Google scholar, and Iranmedex were searched with key words of "DDAVP" or "vasopressin and Hypotension during Hemodialysis." Our review study included articles published in English language from January 1986 to July 2012, as full-text manuscripts, or abstract forms about the effect of vasopressin in prevention of hypotension during HD. Unfortunately, we did not specifically hand search conference proceedings.

\section{Results}

Many studies indicated the effect of vasopressin in the prevention of hypotension during dialysis. However, some studies examined other effects of vasopressin; for example, Beladi Moosavi and colleagues (3) studied its effect in relieving renal colic. Shimizu et al. (61) evaluated the mechanism of vasopressin secretion after infusion of a small amount of hypertonic saline and showed that hypertonic solutions induce a significant increase in arterial plasma osmolality without a significant effect on peripheral venous plasma osmolality. Therefore, it appears that by a mechanism similar to cardiopulmonary recirculation, increment in arterial plasma osmolality enhances vasopressin secretion and raises mean arterial pressure. Mechanism of vasopressin action was examined and concluded that its compensatory mechanism of hypotension and hypovolemia maintains and controls blood pressure, especially in inefficient cases. Mechanism of vasopressin secretion in a small amount of hypertonic saline infusion was studied, and it was found that hypertonic solutions increase arterial osmolality of plasma, but no significant effect on peripheral plasma osmolality. It seems that in ESRD patients undergoing chronic hemodialysis, administration of vasopressin can significantly reduce frequency of the hypotension episodes, which affects the dialysis quality.

\section{Discussion}

Arginine vasopressin (AVP), also known as anti-diuretic hormone $(\mathrm{ADH})$, is derived from a preprohormone precursor. It is synthesized in the hypothalamus and stored at the posterior pituitary gland. It is released in the setting of hyperosmolality or nonosmotic stimuli, including volume depletion, hypotension, and nausea or vomiting. There are three receptors for AVP, including V1a, V1b, and V2 receptors. AVP plays a key role in the regulation of sodium balance and plasma osmolality by increasing water absorption in the distal convoluted tubules and collecting ducts of the kidney via V2 receptors (55). Its antidiuretic property has been exploited clinically for the management of patients with diabetes insipidus and nocturnal enuresis. In addition, there is also some new evidence that AVP may be effective for pain relieving in patients with acute renal colic possibly by its antidiuretic effect and decreasing intraurethral pressure. For example, a study showed that administration of desmopressin $40 \mu \mathrm{g}$ as nasal spray in patients with acute renal colic decreases the pain scores after 30 minutes in a notable percentage of patients without any apparent side effects (56).

Vasopressin is a well-recognized vasoconstrictor by increment of peripheral vascular resistance via V1a receptors activation on vascular smooth muscle, but it appears that this effect is negligible in healthy individuals. However, in the setting of hypotension and hypovolemia, the hemodynamic response to vasopressin becomes an important compensatory mechanism in maintaining arterial pressure and tissue perfusion (56-59). For instance, in patients with septic shock, release of vasopressin (together with other vasoconstrictors) usually increases systemic vascular resistance and elevates blood pressure (57). In addition, in a study conducted in animals with hemorrhagic shock demonstrated that using V1 receptor antagonist increases hypotension (58). The results of Sato et al. (59) and Cignarelli et al. studies also supported the important role of vasopressin in the maintenance of blood pressure. They showed in two separate studies that vasopressin concentrations do not increase in the setting of orthostatic hypotension among diabetic patients with severe diabetic neuropathy (60).

In recent years, it has been observed that vasopressin release (as it would normally be expected) does not increase in the majority of HD patients with recurrent dialysis hypotension (61). Therefore, it is suggested that the vasopressin insufficiency due to decreased synthesis and or secretion may have an important role in the pathogenesis of hemodynamic instability during HD. In addition, as diabetes mellitus is the most common cause of ESRD, the results of Sato et al. and Cignarelli et al. studies also supported that the inappropriately low vasopressin concentrations may be a part of the underlying mechanism for IDH in diabetic patients (59). Shimizu et al. examined whether vasopressin is a part of the mechanism of blood pressure control in ESRD patients receiving hypertonic solution for IDH (61). They evaluated the effects of intravenous infusions of hypertonic saline, glucose, or physiological doses of vasopressin among 42 patients on long-term HD therapy during IDH. The results of the study showed that hypertonic solutions increase plasma 
osmolality and plasma vasopressin levels. In addition, despite hypertonic solutions have been considered to act as plasma volume expanders; however, in the study, blood pressure increased independent of hypertonic saline effect on plasma volume. Therefore, it was suggested that vasopressin secretion due to osmotic stimulation is an important mechanism of blood pressure control. Vasopressin infusion was also increased mean arterial pressure and plasma vasopressin concentrations to the levels similar to those induced by the hypertonic saline and glucose. Finally, they strongly suggested that the osmotic stimulation of vasopressin secretion by hypertonic solutions has an important role in increasing blood pressure among these patients. They also claimed that vasopressin infusion may be an effective therapy to prevent IDH episodes $(61,62)$.

In another study, Shimizu et al. evaluated the mechanism of vasopressin secretion after infusion of a small amount of hypertonic saline and showed that hypertonic solutions induce a significant increase in arterial plasma osmolality without a significant effect on peripheral venous plasma osmolality. Therefore, it appears that by a mechanism similar to cardiopulmonary recirculation, increment in arterial plasma osmolality enhances vasopressin secretion and raises mean arterial pressure (63). To examine the role of insufficient vasopressin secretion in the pathogenesis of IDH, Friess et al. measured plasma vasopressin level in $23 \mathrm{ESRD}$ patients with recurrent symptomatic episodes of hypotension during HD. Vasopressin concentration increased largely in 6 patients with hypotension and nausea during the study, but in the remaining 17 hypotensive patients without nausea, vasopressin level did not significantly increase during HD. Thus, the results of Friess et al. study also suggested the potential role of vasopressin insufficiency in the pathogenesis of IDH (52). The results of Rho et al. study have also clearly supported the finding of the previous article. In their observational pilot study, they assessed and compared the baseline AVP level and trend of AVP with ultrafiltration in patients with and without IDH. They observed that AVP concentration did not increase as much as it would normally be expected in the IDH patients compared with patients without IDH. In their conclusion, they suggested that ESRD patients with symptomatic IDH are unable to increase appropriately AVP secretion during hypotensive episodes (53). In summary, the results of above studies and other articles support the role of vasopressin insufficiency in the pathogenesis of IDH and possibility of AVP as a mechanism of therapy for patients with hemodynamic instability during HD.

However, clinical trials on the vasopressin effect on prevention of IDH are scant. In a double-blind, crossover fashion, Lindberg et al. assessed the efficacy of intranasal lysine vasopressin and placebo in the prevention of hypotension during HD. In their study, 6 patients with refractory hemodialysis-induced hypotension and abnormal autonomic testing were evaluated. The results of the study demonstrated that after using intranasal lysine vasopressin systolic, diastolic, and mean arterial blood pressures were significantly greater at $90 \mathrm{~min}$ of the dialysis session. In addition, the mean number of hypotensive episodes and the total volume of intravenous fluid administered (because of hypotension) decreased (54). van der Zee et al. (29) have also shown the efficacy of vasopressin in this issue and supported the findings of Lindberg et al. study (54). In van der Zee et al. study, the plasma vasopressin concentration during HD was measured and shown that the level of plasma vasopressin did not increase during HD in spite of significant fluid removal. Then, in a randomized, double-blinded and placebo-controlled trial they examined 22 ESRD patients and showed that, compared to a standard hemodialysis, blood pressure was more stable and the incidence of symptomatic hypotension did not increase by greater fluid removal among the patients receiving constant infusion of a nonpressor dose of vasopressin during hemodialysis. Only $9 \%$ of the patients in the vasopressin group (compare with $64 \%$ of the patients receiving placebo) had symptomatic hypotensive episodes. In addition, the increased fluid removal was also achieved only in the vasopressin group during the study. Finally, van der Zee et al. concluded that inadequate vasopressin secretion during $\mathrm{HD}$ is a likely contributor to the hypotension that limits removal of excess extracellular fluid, and administration of exogenous vasopressin, by supporting arterial pressure, may improve cardiovascular stability and facilitates volume removal during $\mathrm{HD}$ (29).

The results of double-blinded and placebo-controlled clinical trial of Beladi Mousavi et al. (64) also supported the findings of van der Zee et al. study (29). They compared the effect of intranasal desmopressin, a synthetic structural analog of antidiuretic hormone and intranasal distilled water in prevention of IDH among patients received ultrafiltration during hemodialysis. In the first month of this study, 17 patients with known symptomatic IDH received nasal spray of distill water as a placebo and after a 30-day washout period, the patients received intranasal desmopressin 30 minutes before all HD sessions. When compared to the placebo group, the incidences of IIDH episodes was significantly lower and the mean arterial blood pressure was significantly higher during hemodialysis with desmopressin (64).

Hypotension during hemodialysis is the most common and important side effect of HD, especially in the elderly and cardiovascular compromised patients. It has a negative impact on health-related quality of life too (70-78). Unfortunately the incidence of this problem is very high and ranges from $15 \%$ to $50 \%$ of dialysis sessions. Many factors have been proposed causing hypotension during HD and different strategies, and a number of pharmacologic agents have been evaluated to prevent IDH. Arginine vasopressin is widely recognized for its role in the regulation of sodium balance and antidiuretic properties. Moreover, it is a well-recognized vasoconstrictor and the 
Beladi Mousavi SS et al.

role of vasopressin insufficiency in the pathogenesis of hemodynamic instability during HD has also been demonstrated in recent years by several observations.

At first Friess et al. (52) and then other researchers showed that vasopressin release (as it would normally be expected) does not increase in the majority of hemodialysis patients with recurrent dialysis hypotension. In addition, Shimizu et al. (61) strongly demonstrated that vasopressin secretion due to osmotic stimulation is an important part of the mechanism of blood pressure control among ESRD patients receiving hypertonic solution for IDH. Hence, it is suggested that intravenous vasopressin and perhaps intranasal vasopressin administration may improve hemodynamic stability among ESRD patients during HD. There are few clinical trials, including van der Zee et al. (29), Beladi Mousavi et al. (64), and Shimizu et al. $(61,63)$ which have carried out on the possible effect of vasopressin in prevention of IDH episodes. All of them suggested that administration of exogenous vasopressin may be significantly associated with a decreased incidence of IDH episodes and cardiovascular stability among ESRD patients in need of volume removal during HD. Although the results of these studies are interesting, the studies have some limitations such as short duration, lack of information regarding the patients, and small number of patients enrolled in the studies. Therefore, further multicenter clinical trials with longer duration and larger number of patients are needed to determine the effect of vasopressin administration for prevention of hypotension during HD. The strength point of our study was its comprehensiveness to review all studies about vasopressin without prejudice. One of the weak points of our study was the use of articles abstract in cases where their full text was not available.

\section{Acknowledgements}

We acknowledge Mr. Mehrdad Zahmatkesh for his assistance in preparing the article.

\section{References}

1. Bregman H, Daugirdas JT, Ing TS. Complications during hemodialysis. In: Daugirdas JT, Ing TS editors. Handbook of Dialysis.. New York: Little, Brown; 1994. p. 149.

2. Tamadon MR, Ardalan MR, Nasri H. World Kidney Day 2013; acute renal injury; a global health warning. J Parathyr Dis. 2014;1(2):27-8.

3. BeladiMousavi SS, Alemzadeh Ansari MJ. Outcome of Patients on Hemodialysis in Khuzestan, Iran. NDT Plus. 2011;4(2):1-2.

4. Dumler F, Stalla K, Mohini R, Zasuwa G, Levin NW. Clinical experience with short-time hemodialysis. Am J Kidney Dis. 1992;19(1):49 56.

5. Beladi Mousavi SS, Hayati F, Alemzadeh Ansari MJ, Valavi E, Cheraghian B, Shahbazian $\mathrm{H}$, et al. Survival at 1, 3, and 5 years in diabetic and nondiabetic patients on hemodialysis. Iran J Kidney Dis. 2010;4(1):74-7.

6. Collins DM, Lambert MB, Tannenbaum JS, Oliverio M, Schwab SJ. Tolerance of hemodialysis: a randomized prospective trial of high-flux versus conventional high-efficiency hemodialysis. J Am Soc Nephrol.1993;4(2):148-54.

7. BeladiMousavi SS, Moradi S, Hayati F, Safaee A, Beladi Mousavi M. Evaluation of Gabapentin effect on muscle cramps in ESRD patients during hemodialysis. Iran J Kidney Dis. 2011;5(2):24-5
8. Skroeder NR, Jacobson SH, Lins LE, Kjellstrand CM. Acute symptoms during and between hemodialysis: the relative role of speed, duration, and biocompatibility of dialysis. Artif Organs 1994;18(12):880-7.

9. Hajivandi A, Amiri M. World kidney day 2014: Kidney disease and elderly. J Parathyr Dis. 2014;2(1):3-4.

10. Milinkovic M, Zidverc-Trajkovic J, Sternic N, Trbojevic-Stankovic J, Maric I, Milic M, et al. Hemodialysis headache. Clin Nephrol. 2009;71(2):158-63.

11. Beladi Mousavi SS, Sametzadeh M, Hayati F, Fatemi SM. Evaluation of acquired cystic kidney disease in patients on hemodialysis with ultrasonography. Iran J Kidney Dis. 2010;4(3):223-6.

12. van der Sande FM, Kooman JP, Leunissen KM. Intradialytic hypotension--new concepts on an old problem. Nephrol Dial Transplant. 2000;15(11):1746-8.

13. Tamadon MR. Secondary hyperparathyroidism and chronic kidney disease. J Parathyr Dis.;1(1):15-6.

14. Skroeder NR, Jacobson SH, Lins LE, Kjellstrand CM. Biocompatibility of dialysis membranes is of no importance for objective or subjective symptoms during or after hemodialysis. ASAIO Trans 1990;36(3):M637-9.

15. Zager PG, Nikolic J, Brown RH, Campbell MA, Hunt WC, Peterson $\mathrm{D}$, et al. "U" curve association of blood pressure and mortality in hemodialysis patients. Medical Directors of Dialysis Clinic, Inc Kidney Int. 1998;54(2):561-9.

16. Shoji T, Tsubakihara Y, Fujii M, Imai E. Hemodialysis-associated hypotension as an independent risk factor for two-year mortal ity in hemodialysis patients. Kidney Int. 2004;66(3):1212-20.

17. Dasselaar JJ, Huisman RM, de Jong PE, Franssen CF. Measurement of relative blood volume changes during haemodialysis: merits and limitations. Nephrol Dial Transplant. 2005;20(10):2043-9.

18. Orofino L, Marcen R, Quereda C, Villafruela JJ, Sabater J, Matesanz $\mathrm{R}$, et al. Epidemiology of symptomatic hypotension in hemodialysis: is cool dialysate beneficial for all patients? Am J Nephrol. 1990;10(3):177-80.

19. Henrich WL. Hemodynamic instability during hemodialysis. Kidney Int. 1986;30(4):605-12.

20. Kouw PM, Kooman JP, Cheriex EC, Olthof CG, de Vries PM, Leunissen KM. Assessment of postdialysis dry weight: a comparison of techniques. J Am Soc Nephrol. 1993;4(1):98-104.

21. Begin V, Deziel C, Madore F. Biofeedback regulation of ultrafiltration and dialysate conductivity for the prevention of hypoten sion during hemodialysis. ASAIO J. 2002;48(3):312-5.

22. Brennan JM, Ronan A, Goonewardena S, Blair JE, Hammes M Shah D, et al. Handcarried ultrasound measurement of the inferior vena cava for assessment of intravascular volume status in the outpatient hemodialysis clinic. Clin J Am Soc Nephrol. 2006;1(4):749-53.

23. Nette RW, van den Dorpel MA, Krepel HP, Ie EH, van den Meiracker AH, Poldermans D, et al. Hypotension during hemodialysis results from an impairment of arteriolar tone and left ventricular function. Clin Nephrol. 2005;63(4):276-83.

24. Shinzato T, Miwa M, Nakai S, Morita H, Odani H, Inoue I, et al. Role of adenosine in dialysis-induced hypotension. J Am Soc Nephrol. 1994;4(12):1987-94

25. Barakat MM, Nawab ZM, Yu AW, Lau AH, Ing TS, Daugirdas JT Hemodynamic effects of intradialytic food ingestion and the effects of caffeine. J Am Soc Nephrol.1993;3(11):1813-8.

26. Noris M, Benigni A, Boccardo P, Aiello S, Gaspari F, Todeschini M et al. Enhanced nitric oxide synthesis in uremia: implications for platelet dysfunction and dialysis hypotension. Kidney Int 1993;44(2):445-50.

27. Yokokawa K, Mankus R, Saklayen MG, Kohno M, Yasunari K, Mina$\mathrm{mi} \mathrm{M}$, et al. Increased nitric oxide production in patients with hypotension during hemodialysis. Ann Intern Med.1995;123(1):35-7.

28. Roy PN, Danziger RS. Dialysate magnesium concentration predicts the occurrence of intradialytic hypotension (abstract). JAm Soc Nephrol. 1996;7(1496).

29. van der Zee S, Thompson A, Zimmerman R, Lin J, Huan Y, Braskett $\mathrm{M}$, et al. Vasopressin administration facilitates fluid removal during hemodialysis. Kidney Int. 2007;71(4):318-24.

30. Masani NN, Miyawaki N, Maesaka JK. A patient with an uncommon etiology of intradialytic hypotension. Semin Dial. 
2005;18(5):435-9.

31. Nasri H. Correlation of serum magnesium with serum levels of 25-hydroxyvitamin D in hemodialysis patients. J Parathyr Dis. 2014;2(1):11-3.

32. Donauer J, Kolblin D, Bek M, Krause A, Bohler J. Ultrafiltration profiling and measurement of relative blood volume as strategies to reduce hemodialysis-related side effects. Am J Kidney Dis. 2000;36(1):115-23.

33. Deziel C, Bouchard J, Zellweger M, Madore F. Impact of hemocontrol on hypertension, nursing interventions, and quality of life: a randomized, controlled trial. Clin JAm Soc Nephrol. 2007;2(4):6618.

34. Basile C, Vernaglione L, Di Iorio B, Bellizzi V, Chimienti D, Lomonte $C$, et al. Development and validation of bioimpedance analysis prediction equations for dry weight in hemodialysis patients. Clin J Am Soc Nephrol. 2007;2(4):675-80.

35. Palmer BF, Henrich WL. Recent advances in the prevention and management of intradialytic hypotension. J Am Soc Nephrol. 2008;19(1):8-11.

36. Kraemer M, Rode C, Wizemann V. Detection limit of methods to assess fluid status changes in dialysis patients. Kidney Int. 2006;69(9):1609-20.

37. van de Pol AC, Frenken LA, Moret K, Baumgarten R, van der Sande FM, Beerenhout CM, et al. An evaluation of blood volume changes during ultrafiltration pulses and natriuretic peptides in the assessment of dry weight in hemodialysis patients. Hemodial Int. 2007;11(1):51-61.

38. Kuhlmann MK, Zhu F, Seibert E, Levin NW. Bioimpedance, dry weight and blood pressure control: new methods and consequences. Curr Opin Nephrol Hypertens. 2005;14(6):543-9.

39. Preventing and managing hypotension. In: Daugirdas JT editor. Seminars in Dialysis. 1994 Wiley Online Library: pp. 276-83.

40. Stiller S, Bonnie-Schorn E, Grassmann A, Uhlenbusch-Korwer I, Mann $\mathrm{H}$. A critical review of sodium profiling for hemodialysis. Semin Dial. 2001;14(5):337-47.

41. Locatelli F, Covic A, Chazot C, Leunissen K, Luno J, Yaqoob M. Optimal composition of the dialysate, with emphasis on its influence on blood pressure. Nephrol Dial Transplant. 2004;19(4):785-96.

42. Sang GL, Kovithavongs C, Ulan R, Kjellstrand CM. Sodium ramping in hemodialysis: a study of beneficial and adverse effects. Am J Kidney Dis. 1997;29(5):669-77.

43. K. Doqi Workgroup . K/DOQI clinical practice guidelines for cardiovascular disease in dialysis patients. Am J Kidney Dis 2005;45(4 Suppl 3):S1-153.

44. Song JH, Park GH, Lee SY, Lee SW, Lee SW, Kim MJ. Effect of sodium balance and the combination of ultrafiltration profile during sodium profiling hemodialysis on the maintenance of the quality of dialysis and sodium and fluid balances. J Am Soc Nephrol. 2005;16(1):237-46.

45. Jacob AD, Elkins N, Reiss OK, Chan L, Shapiro JI. Effects of acetate on energy metabolism and function in the isolated perfused rat heart. Kidney Int. 1997;52(3):755-60.

46. Jindal K, Chan CT, Deziel C, Hirsch D, Soroka SD, Tonelli M, et al. Hemodialysis clinical practice guidelines for the Canadian Society of Nephrology. JAm Soc Nephrol. 2006;17(3 Suppl1):S1-27.

47. Cruz DN, Mahnensmith RL, Brickel HM, Perazella MA. Midodrine and cool dialysate are effective therapies for symptomatic intradialytic hypotension. Am J Kidney Dis. 1999;33(5):920-6.
48. Flynn J3, Mitchell MC, Caruso FS, McElligott MA. Midodrine treatment for patients with hemodialysis hypotension. Clin Nephrol. 1996;45(4):261-7.

49. Montagnac R, Clavel P, Delhotal-Landes B, Flouvat B, Poulain $S$, Schllinger F. Use of midodrine (Gutron) to treat permanent hypotension in a chronic hemodialysis patient. Clin Nephrol. 2001;56(2):162-8.

50. Perazella MA. Pharmacologic options available to treat symptomatic intradialytic hypotension. Am J Kidney Dis. 2001;38(4 Suppl 4):S26-36.

51. Prakash S, Garg AX, Heidenheim AP, House AA. Midodrine appears to be safe and effective for dialysis-induced hypotension: a systematic review. Nephrol Dial Transplant. 2004;19(10):2553-8.

52. Friess U, Rascher W, Ritz E, Gross P. Failure of arginine-vasopressin and other pressor hormones to increase in severe recurrent dialysis hypotension. Nephrol Dial Transplant. 1995;10(8):1421-7.

53. Rho M, Perazella MA, Parikh CR, Peixoto AJ, Brewster UC. Serum vasopressin response in patients with intradialytic hypotension: a pilot study. Clin J Am Soc Nephrol. 2008;3(3):729-35.

54. Lindberg JS, Copley JB, Melton K, Wade CE, Abrams J, Goode D. Lysine vasopressin in the treatment of refractory hemodialysisinduced hypotension. Am J Nephrol. 1990;10(4):269-75.

55. Nielsen S, Chou CL, Marples D, Christensen EI, Kishore BK, Knepper MA. Vasopressin increases water permeability of kidney collecting duct by inducing translocation of aquaporin-CD water channels to plasma membrane. Proc Natl Acad Sci U S A. 1995;92(4):1013-7.

56. BeladiMoosavi SS, Darian AS, Forouzan A, Kalantar H, Masoumi K. Renal Colic Pain Relief by Intranasal Desmopressin. Life Science Journal. 2012;9(4):3354-8.

57. Holmes CL, Patel BM, Russell JA, Walley KR. Physiology of vasopressin relevant to management of septic shock. Chest. 2001;120(3):989-1002.

58. Schwartz J, Reid IA. Effect of vasopressin blockade on blood pressure regulation during hemorrhage in conscious dogs. Endocrinology. 1981;109(5):1778-80.

59. Sato K, Kimura T, Ota K, Shoji M, Ohta M, Yamamoto T, et al. Changes in plasma vasopressin levels and cardiovascular function due to postural changes in diabetic neuropathy. Tohoku JExp Med.1995;177(1):49-60.

60. Cignarelli M, De Pergola G, Paternostro A, Corso M, Cospite MR, Centaro GM, et al. Arginine-vasopressin response to supine-erect posture change: an index for evaluation of the integrity of the afferent component of baroregulatory system in diabetic neuropathy. Diabete Metab.1986;12(1):28-33.

61. Shimizu K, Kurosawa T, Sanjo T. Effect of hyperosmolality on vasopressin secretion in intradialytic hypotension: a mechanistic study. Am J Kidney Dis. 2008;52(2):294-304.

62. Ardalan MR, Sanadgol H, Nasri H, Baradaran A, Rafieian-Kopaei M. Vitamin D therapy in diabetic kidney disease; current knowledge on a public health problem.J Parathyr Dis. 2014;2(1):15-7.

63. Shimizu K, Kurosawa T, Ishikawa R, Sanjo T. Vasopressin secretion by hypertonic saline infusion during hemodialysis: effect of cardiopulmonary recirculation. Nephrol Dial Transplant. 2012;27(2):796-803.

64. Beladi-Mousavi SS, Beladi-Mousavi M, Hayati F, Talebzadeh M. Effect of intranasal DDAVP in prevention of hypotension during hemodialysis. Nefrologia. 2012;32(1):89-93. 